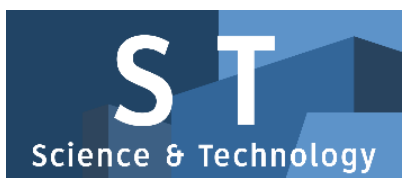

PAPER - OPEN ACCESS

\title{
Konsep Generalized Gradient Pada Optimisasi Nonsmooth
}

\author{
Author : Esther Nababan \\ DOI $\quad: 10.32734 /$ st.v1i2.294 \\ Electronic ISSN $\quad: 2654-7082$ \\ Print ISSN $\quad$ : 2654-7074
}

Volume 1 Issue 2 - 2018 TALENTA Conference Series: Science \& Technology (ST)

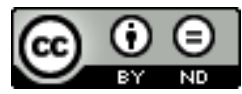

This work is licensed under a Creative Commons Attribution-NoDerivatives 4.0 International License.

Published under licence by TALENTA Publisher, Universitas Sumatera Utara
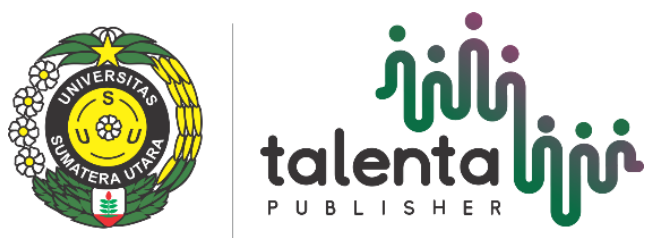


\title{
Konsep Generalized Gradient Pada Optimisasi Nonsmooth
}

\author{
Esther Nababan ${ }^{\mathrm{a} *}$, Pengarapen Bangun ${ }^{\mathrm{a}}$ \\ ${ }^{a}$ Departemen Matematika FMIPA,Universitas Sumatera Utara, Indonesia \\ esther@usu.ac.id; pengarapen@usu.ac.id
}

\begin{abstract}
Abstrak
Tulisan ini merupakan kajian literature mengenai konsep generalized pada optimisasi fungsi nonsmooth. Generalized gradient $\partial \mathrm{f}$ merupakan salah satu pengganti derivative atau turunan fungsi. Generalized gradient dikembangkan dari kenyataan bahwa suatu fungsi tak halus yang memenuhi kondisi Lipschitz disekitar suatu titik $x$ pasti mempunyai turunan berarah di titik $\mathrm{x}$ dalam arah $\mathrm{v}$, yaitu $\mathrm{f}^{\circ}(x ; v)$. Generalized gradient dari fungsi real $f$ di suatu titik $x$ didefinisikan sebagai $\partial \mathrm{f}(x):=\left\{\xi \in \mathrm{R}^{\mathrm{n}}: \mathrm{f}{ }^{\circ}(x ; v) \geq\langle v, \xi\rangle\right.$ untuk semua $v$ di $\left.\mathrm{R}^{\mathrm{n}}\right\}$.

Secara geometri, fungsi nonsmooth dapat dibuktikan mempunyai titik optimal apabila fungsi tersebut konveks. Dengan analisa konveksitas ditunjukkan bahwa syarat perlu untuk titik $\mathrm{x} *$ merupakan titik peminimum dari fungsi tak halus $\mathrm{f}(\mathrm{x})$ adalah $0 \in \partial \mathrm{f}(\mathrm{x})$.
\end{abstract}

Kata kunci : Optimisasi; Fungsi Non Smooth; Generalized Gradient

\section{Pendahuluan}

Pengertian "Nonsmooth" atau "tak halus" untuk suatu fungsi dalam matematika merujuk pada suatu keadaan dimana "kehalusan / smoothness" yang artinya "dapat diturunkan / differentiable" tidak selalu dapat diasumsikan atau tidak dapat dijamin ada pada suatu titik didalam fungsi. Phenomena nonsmooth dalam matematika dan optimisasi muncul lebih umum dan sering, sehingga perlu ditinjau properti differential dari fungsi-fungsi yang tak dapat diturunkan (nondifferentiable).

Dalam menyelesaikan masalah Optimisasi suatu fungsi $\mathrm{f}(\mathrm{x})$ secara umum, titik optimal $\mathrm{x}^{*}$ harus memenuhi suatu kondisi atau syarat perlu dan cukup, dimana kondisi tersebut antara lain menyertakan turunan fungsi objektif dan adanya suatu pengali Lagrange.

Dari pengetahuan kalkulus, fungsi yang dapat diturunkan adalah fungsi halus, sedangkan untuk fungsi yang tidak halus ada suatu alternatif pengganti turunan [1]. Pendekatan yang digunakan adalah pemisalan suatu fungsi tidak halus (selanjutnya disebut fungsi nosmooth) sebagai fungsi jarak dc dari $\mathrm{C}$ yang merupakan himpunan bagian tertutup dari R. Fungsi ini didefinisikan sebagai :

$$
d_{c}(x)=\min \{|x-c|: c \in C\}
$$


dimana $|\cdot|$ adalah norm diruang Euclid. Fungsi jarak ini merupakan jembatan antara geometri analitik dan konsep geometri dalam mengembangkan teori di ruang Banach untuk menentukan alternatif turunan untuk fungsi nonsmooth. Selanjutnya dengan pendekatan analisis koveksitas dapat diturunkan syarat perlu untuk suatu titik $\mathrm{x}^{*}$ merupakan peminimum dari fungsi tak halus.

\section{Pembahasan}

Misalkan Y adalah himpunan bagian dari X. Suatu fungsi f : Y $\rightarrow \mathrm{R}$ dikatakan memenuhi kondisi Lipschitz (pada Y) dimana untuk suatu skalar K yang nonnegatif,

$$
\left|\mathrm{f}(y)-\mathrm{f}\left(y^{\prime}\right)\right| \leq K|| y-y^{\prime}||
$$

untuk semua titik-titik y, y' di Y. Dapat juga dikatakan bahwa f Lipschitz (dari rank K) disekitar x jika untuk suatu $\in>0$, f memenuhi kondisi Lipshitz (dari rank K) pada himpunan $\mathrm{x}+\in \mathrm{B}$ dimana $\mathrm{B}$ adalah bola terbuka.

Misalkan f Lipschitz disekitar suatu titik $\mathrm{x}$, dan v suatu vektor di X. Generalized directional derivative (turunan berarah secara umum) dari $f$ dalam arah $v$, yaitu $\mathrm{f}^{\mathrm{o}}(\mathrm{x} ; \mathrm{v})$ didefinisikan sebagai berikut :

$$
f^{0}(x ; v)=\lim _{\substack{\mathrm{y} \rightarrow \mathrm{x} \\ \mathrm{t} \downarrow 0}} \sup \frac{f(y+t v)-f(y)}{t}
$$

dimana y adalah vektor di $\mathrm{X}$ dan $\mathrm{t}$ suatu skalar yang positip.

Selanjutnya $\mathrm{f}^{\mathrm{o}}$ dikembangkan dengan dasar proposisi berikut :

Proposisi 1:

Misalkan f Lipschitz dari rank K disekitar x. Maka

a. Fungsi $\mathrm{v} \rightarrow \mathrm{f}^{\mathrm{o}}(\mathrm{x} ; \mathrm{v})$ terbatas, homogen posistip dan subadditive di $\mathrm{X}$, dan memenuhi $\left|\mathrm{f}^{\mathrm{o}}(\mathrm{x} ; \mathrm{v})\right| \leq \mathrm{K}\|\mathrm{v}\|$

b. $\mathrm{f}^{\circ}(\mathrm{x} ; \mathrm{v})$ upper semi kontinu sebagai fungsi dari $(\mathrm{x} ; \mathrm{v})$ dan sebagai fungsi dari hanya $\mathrm{v}$, $\mathrm{f}$ Lipschitz dari rank $\mathrm{K}$ pada $X$.

c. $\mathrm{f}^{\mathrm{o}}(\mathrm{x} ;-\mathrm{v})=(-\mathrm{f})^{\mathrm{o}}(\mathrm{x} ; \mathrm{v})$

Dibawah kondisi Proposisi 1 ada paling sedikit satu fungsi linier $\xi: X \rightarrow R$ sedemikian hingga untuk setiap v di $\mathrm{X}, \mathrm{f}^{\mathrm{o}}(\mathrm{x} ; \mathrm{v}) \geq \xi(\mathrm{v})$. $\xi$ terbatas dan merupakan elemen dari ruang dual $\mathrm{X}^{*}$ dari fungsi linier kontinu di $\mathrm{X}$.

Selanjutnya $\mathrm{f}(\xi)$ dituliskan sebagai $\langle\mathrm{v}, \xi\rangle$ atau $\langle\xi, \mathrm{v}\rangle$.

Generalized Gradient dari $\mathrm{f}$ pada $\mathrm{x}$, yaitu $\partial \mathrm{f}(\mathrm{x})$ adalah himpunan bagian dari $\mathrm{X}^{*}$ yaitu

$\left\{\xi \in \mathrm{X}^{*}: \mathrm{f}^{\mathrm{o}}(\mathrm{x} ; \mathrm{v}) \geq\langle\mathrm{v}, \xi\rangle \forall \mathrm{v}\right.$ di $\left.\mathrm{R}^{\mathrm{n}}\right\}$

Norm di $X^{*}$, yaitu $\|\xi\|_{*}$ adalah :

$$
\|\xi\| *=\sup \{\langle\mathrm{v}, \xi\rangle: \mathrm{v} \in \mathrm{X},\|\mathrm{v}\| \leq 1\}
$$

dan $\mathrm{B} *$ adalah bola terbuka di $\mathrm{X}^{*}$.

Berikut adalah beberapa proposisi dasar dari generalized gradient.

Proposisi 2:

Misalkan f suatu Lipschitz dari rank K disekitar x. Maka :

1. $\partial \mathrm{f}(\mathrm{x})$ himpunan bagian tidak kosong, konveks, kompak lemah (weak compact) dari $\mathrm{X}^{*}$ dan $\|\xi\|_{*} \leq \mathrm{K}$ untuk setiap $\xi$ di $\partial f(x)$.

2. Untuk setiap v di $X, f^{o}(x ; v)=\operatorname{maks}\{\langle v, \xi\rangle ; \xi \in \partial f(x)\}$ 
Dalam kaitannya dengan optimisasi fungsi nonsmooth, Brocket [2] memberikan penjabaran yang lebih jelas dengan memberikan ilustrasi secara geometri, sedangkan, Clarke [3] mengembangkan teori untuk menentukan kondisi optimal suatu fungsi nonsmooth dengan menggunakan properti dari konveksitasnya. Rockafellar [4] memperlihatkan sifat konveks dari fungsi nonsmooth dengan pendekatan teori topologi di ruang Banach.

Selanjutnya konsep dasar generalized gradient secara umum ini dikembangkan dan diterapkan pada masalah optimisasi nonsmooth.

Sebagai pengganti derivative atau turunan fungsi adalah yang disebut generalized gradient. Generalized gradient ini dapat didefinisikan untuk jenis- jenis fungsi umumnya.

Pemisalan akan dimulai dengan himpunan nilai fungsi real Lipschitz yang terdefinisi di $R^{\mathrm{n}}$. Misalkan $\mathrm{f}: \mathrm{R}^{\mathrm{n}} \rightarrow \mathrm{R}$, dan misalkan $\mathrm{x}$ suatu titik di $\mathrm{R}^{\mathrm{n}}$. Fungsi f dikatakan Lipschitz didekat $\mathrm{x}$ jika terdapat skalar $\mathrm{K}$ dan suatu bilangan positip $\varepsilon$ sedemikian hingga kondisi berikut dipenuhi :

$$
\left|\mathrm{f}\left(x^{\prime \prime}\right)-\mathrm{f}\left(x^{\prime}\right)\right| \leq K\left\|y^{\prime \prime}-x^{\prime}\right\|
$$

untuk semua $x^{\prime \prime}, x^{\prime}$ di $x+\varepsilon B$.

$\mathrm{B}$ adalah bola terbuka di $\mathrm{R}^{\mathrm{n}}$, sehingga $\mathrm{x}+\varepsilon \mathrm{B}$ merupakan bola terbuka dengan jari-jari $\varepsilon$ disekitar $\mathrm{x}$. Selanjutnya akan ditinjau diferensial dari fungsi $f$ dimana $f$ tidak harus dapat diturunkan di x. Generalized directional derivative (turunan berarah secara umum) dari f dalam arah $v$, yaitu $\mathrm{f}^{\mathrm{o}}(\mathrm{x} ; \mathrm{v})$ didefinisikan sebagai berikut :

$$
f^{0}(x ; v)=\lim _{\substack{\mathrm{y} \rightarrow \mathrm{x} \lambda \\ \lambda \downarrow 0}} \sup \frac{f(y+t v)-f(y)}{t}
$$

Selisih kuosien adalah $\mathrm{K}|\mathrm{v}|$ (untuk y cukup dekat $\mathrm{x}$ dan $\lambda$ cukup kecil mendekati 0) didalam kondisi Lipschitz sehingga $\mathrm{f}{ }^{\circ}(\mathrm{x} ; \mathrm{v})$ suatu besaran terbatas. Pendefinisian generalized directional derivative tidak harus dengan cara diatas. Kenyataan bahwa sebagai fungsi dari $\mathrm{v}, \mathrm{f}^{\circ} \quad(\mathrm{x} ; \mathrm{v})$ homogen positip dan subadditive memberikan suatu kemungkinan untuk mendefinisikan suatu himpunan kosong $\partial \mathrm{f}(\mathrm{x})$, generalized gradient dari $\mathrm{f}$ di $\mathrm{x}$, sebagai berikut

$\partial \mathrm{f}(\mathrm{x}):=\left\{\xi \in \mathrm{R}^{\mathrm{n}}: \mathrm{f}^{\mathrm{o}}(\mathrm{x} ; \mathrm{v}) \geq\langle\mathrm{v}, \xi\rangle\right.$ untuk semua $\mathrm{v}$ di $\left.\mathrm{R}^{\mathrm{n}}\right\}$

Dengan memperhatikan properti dari $\mathrm{f}^{\circ}$, dapat ditunjukkan bahwa $\partial \mathrm{f}(\mathrm{x})$ adalah himpunan bagian kompak dan konveks tak kosong dari $\mathrm{R}^{\mathrm{n}}$. Untuk suatu $\mathrm{v}, \mathrm{f}^{\mathrm{o}}(\mathrm{x} ; \mathrm{v})=\operatorname{maks}\{\langle\mathrm{v}, \xi\rangle: \xi \in \partial \mathrm{f}(\mathrm{x})\}$, yang artinya dengan mengetahui $\mathrm{f}^{\mathrm{o}}$ maka $\partial \mathrm{f}(\mathrm{x})$ dapat diketahui. Jika $\mathrm{f}$ fungsi halus, $\partial \mathrm{f}(\mathrm{x})$ menjadi himpunan tunggal $\{\nabla \mathrm{f}(\mathrm{x})\}$, dan jika $\mathrm{f}$ konveks, maka $\partial \mathrm{f}(\mathrm{x})$ sama dengan apa yang disebut subdifferensial pada analisa konveks, yaitu himpunan vektor $\xi$ di $\mathrm{R}^{\mathrm{n}}$ yang memenuhi :

$$
f(x+u)-f(x) \geq\langle u, \xi\rangle \quad \text { untuk setiap } u \text { di } R^{n}
$$

Perhitungan $\partial \mathrm{f}(\mathrm{x})$ dari definisi ini secara numerik sangat sulit. Oleh sebab itu dicari suatu bentuk lain yang ekivalen dalam mendefinisikan generalized gradient. Salah satu alternatif adalah yang berdasarkan teorema Rademacher yang menyatakan bahwa suatu fungsi yang locally Lipschitz pasti terdiferensial hampir dimana-mana (dalam ukuran Lebesque) Misalkan $\Omega$ suatu himpunan titik-titik didalam $x+\varepsilon B$ dimana $\mathrm{f}$ tak terdiferensial, dan misalkan $\mathrm{S}$ suatu himpunan lain, yaitu himpunan nol. Karakterisasi dari generalized gradient adalah :

$$
\partial \mathrm{f}(\mathrm{x})=\operatorname{co}\left\{\lim \nabla \mathrm{f}\left(\mathrm{x}_{\mathrm{i}}\right): \mathrm{x}_{\mathrm{i}} \rightarrow \mathrm{x}, \mathrm{x}_{\mathrm{i}} \notin \mathrm{S}, \mathrm{x}_{\mathrm{i}} \notin \Omega_{\mathrm{f}}\right\}
$$

Dengan kata lain $\partial \mathrm{f}(\mathrm{x})$ adalah conveks hull dari semua titik-titik dari $\lim \nabla \mathrm{f}\left(\mathrm{x}_{\mathrm{i}}\right)$, dimana $\left\{\mathrm{x}_{\mathrm{i}}\right\}$ suatu baris yang konvergen ke $\mathrm{x}$. $\partial \mathrm{f}(\mathrm{x})$ dapat direduksi menjadi derivative jika $\mathrm{f} \in \mathrm{C}^{\prime}$, dan menjadi subdiferensial jika f konveks.

Berikut ini adalah contoh perhitungan generalized gradient suatu fungsi.

Dalam hal ini $X=R$ dan $f(x)=|x|(f$ Lipschitz melalui ketaksamaan segitiga $)$. 
Jika x positif mutlak, dapat dihitung :

$$
f^{0}(x ; v)=\lim _{\substack{\mathrm{y} \rightarrow \mathrm{x} \\ \mathrm{t} \downarrow 0}} \sup \frac{y+t v-y}{t}=v
$$

Jadi $\partial f(x)$, himpunan dari bilangan-bilangan $\xi$ yang memenuhi $v \geq \xi \mathrm{v}$ untuk semua v, menjadi tunggal $\{1\}$. Analog, $\partial \mathrm{f}(\mathrm{x})=\{-1\}$ jika $\mathrm{x}<0$. Selanjutnya jika $\mathrm{x}=0$, didapat :

$$
f^{0}(x ; v)=-v=\left\{\begin{array}{c}
v \\
\text { jika } v<<0
\end{array}\right.
$$

yaitu $\mathrm{f}^{\mathrm{o}}(\mathrm{x} ; \mathrm{v})=|\mathrm{v}|$. Maka $\partial \mathrm{f}(0)$ terdiri dari $\xi$ yang memenuhi $|\mathrm{v}| \geq \xi \mathrm{v}$ untuk semua $\mathrm{v}$, yaitu $\partial \mathrm{f}(0)=[-1,1]$

Selanjutnya untuk dapat menggambarkan konsep generalized gradient ini secara geometri, perlu ditinjau tangen cone dan normal cone. Misalkan $\mathrm{C}$ suatu himpunan bagian tak kosong dari $\mathrm{R}^{\mathrm{n}}$. Fungsi Lipschitz tak terdiferensial yang berkaitan dengan $C$ adalah jarak fungsi dari fungsi Lipschitz tak terdiferensial tersebut yaitu $d_{c}$, yang didefinisikan sebagai

$\mathrm{d}_{\mathrm{c}}(\mathrm{x})=\min \{|\mathrm{x}-\mathrm{c}|: \mathrm{c} \in \mathrm{C}\}$.

Generalized directional derivative yang telah terdefinisi sebelumnya dapat digunakan untuk mengembangkan suatu tangen yang tidak memerlukan $\mathrm{C}$ halus atau konveks. Tangen cone $\mathrm{T}_{\mathrm{c}}(\mathrm{x})$ terhadap $\mathrm{C}$ pada titik $\mathrm{x}$ di $\mathrm{C}$ didefinisikan sebagai berikut

$\mathrm{T}_{\mathrm{c}}(\mathrm{x}):=\left\{\mathrm{v} \in \mathrm{R}^{\mathrm{n}}: \mathrm{d}_{\mathrm{c}}{ }^{\circ}(\mathrm{x} ; \mathrm{v})=0\right\}$

Definisikan $\mathrm{N}_{\mathrm{c}}(\mathrm{x})$ suatu normal cone terhadap $\mathrm{C}$ di $\mathrm{x}$ sebagai

$\mathrm{N}_{\mathrm{c}}(\mathrm{x}):=\left\{\xi:\langle\xi, \mathrm{v}\rangle \leq 0\right.$ untuk semua $\mathrm{v}$ di $\left.\mathrm{T}_{\mathrm{c}}(\mathrm{x})\right\}$

Hal ini diikuti oleh $\mathrm{N}_{\mathrm{c}}(\mathrm{x})$ merupakan convex cone tertutup yang dibangun oleh $\partial_{\mathrm{c}} \mathrm{f}(\mathrm{x})$. dibuktikan bahwa suatu vektor v merupakan bagian dari $\mathrm{T}_{\mathrm{c}}(\mathrm{x})$ jika dan hanya jika kondisi berikut dipenuhi :

Untuk setiap barisan $x_{i}$ di $C$ konvergen ke $x$ dan setiap barisan $t_{i}$ di $(0, \propto)$ kovergen ke 0 , ada barisan $v_{i}$ yang konvergen ke $\mathrm{v}$ sedemikian hingga $\mathrm{x}_{\mathrm{i}}+\mathrm{t}_{\mathrm{i}} \mathrm{v}_{\mathrm{i}}$ merupakan bagian dari $\mathrm{C}$ untuk semua $\mathrm{i}$.

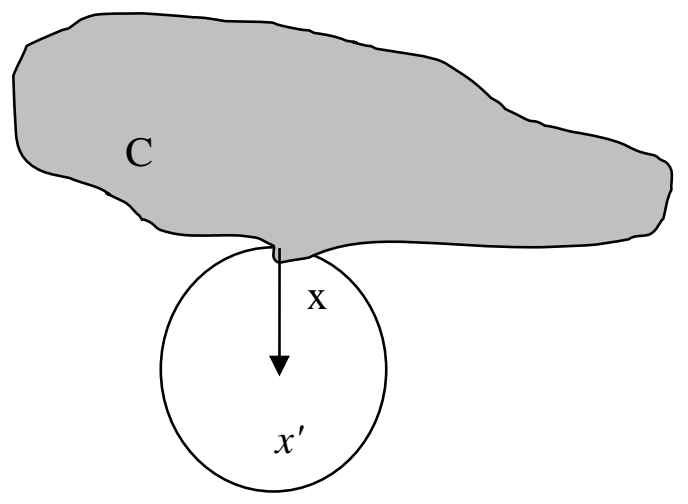

Gambar 1. Vektor $\mathrm{x}^{\prime}-\mathrm{x}$ tegak lurus terhadap C di titik $\mathrm{x}$.

Suatu vektor tidak nol $v$ tegak lurus ke $\mathrm{C}$ pada titik $x$ di $\mathrm{C}(v \perp \mathrm{C}$ di $x)$ jika $v=x^{\prime}-x$, dimana titik $x^{\prime}$ mempunyai satu-satunya titik terdekat $x$ di C. (Ekivalen dengan $v=x^{\prime}-x$, dimana ada suatu bola tertutup dengan pusat $\mathrm{x}^{\prime}$ yang bersinggungan dengan $\mathrm{C}$ hanya di titik $x^{\prime}$ (lihat gambar 1)

Hal ini memperlihatkan bahwa :

$\mathrm{N}_{\mathrm{c}}(x)=\operatorname{co}\left\{\lambda \lim \left(v_{i} /\left|v_{i}\right|\right): \lambda \geq 0, v_{i} \perp \mathrm{C}\right.$ di $\left.x_{i}, x_{i} \rightarrow x, x_{i} \rightarrow 0\right\}$ 
Generalized gradient dapat dikembangkan juga dengan menggunakan pendekatan goemetri. Misalkan $\mathrm{C}$ suatu himpunan bagian tak kosong dari $\mathrm{X}$. Fungsi jarak $\mathrm{d}_{\mathrm{c}}(\bullet): \mathrm{X} \rightarrow \mathrm{R}$ didefinisikan sebagai $: \mathrm{d}_{\mathrm{C}}(\mathrm{x})=\min \{|\mathrm{x}-\mathrm{c}|: \mathrm{c} \in \mathrm{C}\}$

Jika $\mathrm{C}$ tertutup, maka $\mathrm{x} \in \mathrm{C}$ jika dan hanya jika $\mathrm{d}_{\mathrm{C}}(\mathrm{x})=0$. Fungsi $\mathrm{d}_{\mathrm{C}}$ tidak terdiferensial, tetapi Lipschitz secara lokal. Konsep generalized gradient dari fungsi $\mathrm{d}_{\mathrm{C}}$ ini akan digunakan untuk mengembangkan konsep baru mengenai tangen dan normal terhadap himpunan sebarang C. Selanjutnya akan dikaji karakter dari tangen dan normal ini dari sisi topologi. Tangen dan normal yang didefinisikan disini dapat direduksi kedalam suatu masalah fungsi halus atau masalah konveks. Kemudian mengindikasikan bagaimana ilustrasi geometri ini dapat mengarah ke pengembangan definisi dari generalized gradient $\partial \mathrm{f}$ dari suatu fungsi f yang tidak perlu Lipschitz.

\section{$\underline{\text { Proposisi } 3}$}

Suatu fungsi dC memenuhi kondisi Lipschitz global berikut pada $X$ :

$|\mathrm{dC}(\mathrm{x})-\mathrm{dC}(\mathrm{y})| \leq\|\mathrm{x}-\mathrm{y}\|$

Misalkan $\mathrm{x}$ suatu titik di C. Suatu vektor $\mathrm{c}$ di $\mathrm{X}$ adalah tangen terhadap $\mathrm{C}$ di $\mathrm{x}$ dengan

$\mathrm{d}^{\circ} \mathrm{C}(\mathrm{x} ; \mathrm{v})=0$. Himpunan semua tangen terhadap $\mathrm{C}$ di $\mathrm{x}$ dituliskan sebagai $\mathrm{TC}(\mathrm{x})$.

Proposisi 3 mengakibatkan TC (x) merupakan cone konveks tertutup didalam X, khususnya TC (x) selalu mengandung 0 .

Cone normal terhadap $\mathrm{C}$ di $\mathrm{x}$ melalui polaritas dengan $\mathrm{TC}(\mathrm{x})$ :

$\mathrm{NC}(\mathrm{x}) .=\left\{\xi \in \mathrm{X}^{*}:\langle\xi, \mathrm{v}\rangle \leq 0\right.$ untuk semua $\mathrm{v} \operatorname{di} \mathrm{TC}(\mathrm{x})$.

Selanjutnya karakteristik dari NC (x) yang akan dibahas adalah dalam bentuk generalized gradient.

\section{$\underline{\text { Proposisi } 4}$}

$\mathrm{NC}(\mathrm{x})=\mathrm{cl}\{\underset{\lambda \geq 0}{\cup \lambda \partial \mathrm{dC}(\mathrm{x})\} .}$

dimana cl adalah closur / penutup.

Misalkan $\mathrm{f}$ Lipschitz dari rank $\mathrm{K}$ pada himpunan S. Misalkan $\mathrm{x}$ unsur dari himpunan $\quad \mathrm{C} \subset \mathrm{S}$ dan $\mathrm{f}$ mempunyai minimum pada $C$ di $x$. Maka untuk suatu $K \geq K$, fungsi $g(y)=f(y)+K d C(y)$ mencapai minimumnya pada $S$ di $x$. Jika $\mathrm{K}>\mathrm{K}$ dan $\mathrm{C}$ tertutup, maka suatu titik lain peminimum g di $\mathrm{S}$ harus terletak pada $\mathrm{C}$.

Misalkan $\mathrm{f}$ Lipschitz didekat $\mathrm{x}$ dan mencapai minimumnya pada $\mathrm{C}$ di $\mathrm{x}$, maka dapat dibuktikan bahwa $0 \in \partial \mathrm{f}(\mathrm{x})+$ $\mathrm{NC}(\mathrm{x})$.

Generalized gradient diperluas lagi kedalam suatu konsep geometri yang dinamakan hypertangen dan epigraph. Semua konsep merupakan alternatif untuk menghitung turunan suatu fungsi nonsmooth, dimana setiap fungsi nonsmooth mempunyai karakter yang berbeda-beda. Konsep generalized gradient dapat diterapkan pada perhitungan turunan fungsi dengan terlebih dahulu mempelajari karakter fungsi nonsmooth yang akan dicari titik optimalnya. Beberapa properti yang didapat dari karakter fungsi kemudian dikaji secara geometri maupun dengan teori kalkulus untuk kemudian mendapatkan rumusan syarat perlu dan cukup yang harus dipenuhi oleh suatu titik x pada suatu fungsi nonsmooth untuk dapat merupakan titik optimal.

Misalkan X suatu ruang Banach. Masalah program matematik adalah meminimumkan suatu fungsi $\mathrm{f}(\mathrm{x})$ pada $\mathrm{X}$ dengan kendala yang terdiri dari 3 jenis :

i) Kendala ketaksamaan $: \mathrm{g}_{\mathbf{i}}(\mathrm{x}) \leq 0, \mathrm{i}=1,2, \ldots, \mathrm{n}$, dimana setiap $\mathrm{g}_{\mathrm{i}}$ adalah fungsi real di $\mathrm{X}$.

ii) Kendala kesamaan $: h_{j}(x)=0, j=1,2, \ldots, m$, dimana setiap $h_{j}$ adalah suatu fungsi real di $X$.

iii)Kendala abstrak $: \mathrm{x} \in \mathrm{C}$, dimana $\mathrm{C}$ adalah himpunan bagian dari $\mathrm{X}$.

iv) Kendala jenis i) dan ii) selalu dapat diinterpretasikan dalam kendala jenis iii), tentunya dengan mendefinisikan C.

Jika fungsi $\mathrm{F}(\mathrm{x})$ Lipschitz, maka generalized gradien $\partial \mathrm{F}\left(\mathrm{x}^{*}\right)$ ada dan merupakan himpunan tak kosong yang konveks dan kompak di $\mathrm{R}^{\mathrm{n}}$, yaitu :

$\partial \mathrm{F}(\mathrm{x} *)=\operatorname{conv}\left(\nabla \mathrm{F}_{\mathrm{i}}(\mathrm{x}): \mathrm{i} \in \mathbf{A}(\mathrm{x})\right\}$

Syarat perlu untuk $\mathrm{x}^{*}$ merupakan titik minimum lokal dari fungsi nonsmooth $\mathrm{F}(\mathrm{x})$ adalah

$0 \in \partial \mathrm{F}\left(\mathrm{x}^{*}\right)$. Pada setiap titik $x$, $\mathrm{F}$ dapat dituliskan sebagai : 
$\forall \mathrm{x}$ dilingkungan $x$ dimana $\mathbf{A}(x)=\left\{\mathrm{i} \in 1, \ldots, \mathrm{m}: \mathrm{f}(x)=\mathrm{f}_{\mathrm{i}}(x)\right\}$

Jika $\mathrm{x}^{(\mathrm{k})} \rightarrow \mathrm{x}$ suatu barisan berarah dalam arah $\mathrm{s}, \mathrm{x}(\mathrm{k})=\mathrm{x}+\alpha(\mathrm{k}) \mathrm{s}(\mathrm{k})$ dimana $\alpha(\mathrm{k}) \geq 0+,\|\mathrm{s}(\mathrm{k})\|=1$ dan $\mathrm{s}^{(\mathrm{k})} \rightarrow \mathrm{s}$ jika $\alpha^{(\mathrm{k})} \rightarrow 0$, maka terdapat :

$$
\lim \frac{F\left(x^{(k)}-F(x)\right)}{k \rightarrow \infty \alpha^{(k)}}=F^{\prime}(x ; s)
$$

$\mathrm{F}^{\prime}(\mathrm{x} ; \mathrm{s})$ adalah turunan berarah yang didefinisikan sebagai :

$$
F^{\prime(x ; s)}=\lim _{\alpha \downarrow 0} \frac{F(x+\alpha \mathrm{k})-F(x)}{\alpha}
$$

Syarat perlu untuk titik $\mathrm{x}^{*}$ merupakan titik optimal dari $\mathrm{F}$ adalah $\mathrm{F}^{\prime}\left(\mathrm{x}^{*} ; \mathrm{s}\right) \geq 0 \forall \mathrm{s} \in \mathrm{R}^{\mathrm{n}}$.

Karena F Lipschitz lokal, maka

$$
\mathrm{F}^{\prime}(\mathrm{x} ; \mathrm{s})=\max \mathrm{s}_{\mathrm{u} \in \partial \mathrm{T}(\mathrm{x})}^{\mathrm{T}} \text { an } 0 \in \partial \mathrm{f}\left(\mathrm{x}^{*}\right)
$$

Syarat perlu :

Jika $x^{*}$ merupakan titik minimum lokal, maka $0 \in \partial \mathrm{f}\left(\mathrm{x}^{*}\right)$.

Dengan menggunakan, syarat perlu menjadi :

$\exists \lambda_{i}^{*} \geq 0, i \in \mathbf{A}\left(x^{*}\right), \quad \Sigma \lambda_{i}^{*}=1 \quad i \in \mathbf{A}\left(x^{*}\right)$

dimana $\lambda$ adalahpengali Lagrange, sedemikian hingga :

$$
\Sigma \lambda_{i}^{*} \nabla f_{i}(x)=0 \quad i \in \mathbf{A}\left(x^{*}\right)
$$

Syarat cukup orde-1 adalah $\mathrm{F}^{\prime}(\mathrm{x} ; \mathrm{s})>0 \forall \mathrm{s} \neq 0$, yang dapat dibuktikan ekivalen dengan $0 \in \operatorname{int} \partial \mathrm{F}\left(\mathrm{x}^{*}\right)$. Syarat cukup orde-2 dapat diinterpretasikan sebagai kurva F pada arah non-negatif dengan kemiringan nol, yaitu F' $(x ; s)=0$.

Bedasarkan bentuk optimisasi dinamik (dinamic optimization), dengan karakter masing-masing masalah optimisasi yang berbeda, dikenal 3 kategori masalah secara umum. Yaitu masalah optimisasi Bolza atau Problem Bolza $\left(\mathrm{P}_{\mathrm{B}}\right)$, masalah optimisasi dengan fungsi kontrol / kontrol optimum $\left(\mathrm{P}_{\mathrm{C}}\right)$ dan masalah optimisasi Diferensial Inclusion $\left(\mathrm{P}_{\mathrm{D}}\right)$. Ketiga masalah tersebut mempunyai fungsi objektif yang non smooth. Demikian juga halnya dengan jenis turunan / derivatif dari suatu fungsi nonsmooth; dengan karakter fungsi yang berbeda perlu terlebih dahulu dikaji jenis derivativ yang dimiliki fungsi tersebut, apakah Gateaux derivative, Frechet derivative atau jenis derivative lainnya untuk kemudian secara lebih spesifik dapat diteliti lebih lanjut karakter dari fungsinya.

\section{Kesimpulan}

Generalized gradient berawal dari kenyataan bahwa suatu fungsi tak halus yang memenuhi kondisi Lipschitz disekitar suatu titik $x$ pasti mempunyai turunan berarah. Dengan demikian untuk mencari turunan suatu fungsi tak halus dititik ekstrim, perlu ditinjau turunan berarah fungsi tersebut di suatu titik $x$ dari arah kiri maupun arah kanan.

Di setiap titik patah terdapat generalized gradient yang berbeda nilainya pada masing-masing titik patah. Generalized gradient dari fungsi $f$ tak halus di suatu titik $x$ didefinisikan sebagai :

$\partial \mathrm{f}(x):=\left\{\xi \in \mathrm{R}^{\mathrm{n}}: \mathrm{f}^{\mathrm{o}}(x ; v) \geq\langle v, \xi\rangle\right.$ untuk semua $v$ di $\left.\mathrm{R}^{\mathrm{n}}\right\}$.

Dengan analisis konveksitas dapat dibuktikan bahwa $0 \in \partial \mathrm{f}(x)$.

Generalized gradient fungsi tak halus disuatu titik patah tidak unik. Jika f Lipschitz didekat $\mathrm{x}$ dan $\mathrm{X}$ dimensi hingga, maka $\partial \mathrm{f}(\mathrm{x})$ tereduksi menjadi tunggal.

Secara geometri fungsi nonsmooth dapat dibuktikan mempunyai titik optimal apabila fungsi tersebut konveks. Dengan analisa konveksitas ditunjukkan bahwa jika fungsi tak halus $\mathrm{f}$ mempunyai titik ekstrim (minimum atau maksimum) di $\mathrm{x}$, maka $0 \in \partial \mathrm{f}(\mathrm{x})$. Kondisi optimal dari masalah optimisasi nonsmooth dapat diturunkan dengan menggunakan generalized gradien dan analisis konveksitas. 


\section{Daftar Pustaka}

[1] Grossman, Stanley I., (1977), Calculus, Academic Press Inc. , London

[2] Brockett, R.W. (1976). Nonlinear Systems and Differential Geometry, Proc IEEE 64, 61-72

[3] Clarke, Frank H.(1983) Optimization and Nonsmooth Analysis, A Wiley-Interscience Publication (1983)

[4] Rockafellar, R.T. (1996), The Theory of Subgradients and Its Applications to Problems of Optimization : Convex and Nonconvex Functions, Helderman Verlag, Berlin.

[5] Clarke, Frank H.(1975a) Generalized Gradients and Its Applications, Trans. Am. Math. Soc. 205,247-262

[6] Conn A.R dan Y. Li, An Approach to Nonlinear $L_{\infty}$, Tech. Rep. CS-88-39, Department of Computer Science, University of Waterloo, Ontario N2L 3G1, Canada (1989)

[7] Fletcher, R., Practical Methods of Optimization, John Wiley and Sons, New York and Toronto (1987)

[8] Rockafellar, R.T. (1967), Convex Analysis, Princeton University Press, Princeton, NJ 